\title{
Família e Cuidados Paliativos em Pediatria: Desafios à Garantia do Cuidado
}

\author{
Family and Palliative Care in Pediatrics: Challenges in Guaranteeing Care \\ Familia y Cuidados Paliativos en Pediatría: Desafíos para Garantizar la Atención
}

\author{
Gabrieli Branco Martins'; Senir Santos da Hora²
}

\section{INTRODUÇÃO}

O presente artigo busca apresentar algumas reflexôes tecidas a partir do cotidiano de trabalho do Serviço Social numa clínica de pediatria oncológica sobre as questóes sociais que envolvem as famílias e o cuidado paliativo pediátrico.

Para a filosofia, a palavra "cuidado" deriva do latim "cura". A forma mais antiga de se utilizar a palavra cura no sentido de cuidado era em contexto de relaçóes de amor e amizade. A noção de cura não se restringe apenas ao afastamento da dor, do sofrimento e da morte, mas também inclui a busca pela ampliação da capacidade de autonomia e qualidade de vida da própria pessoa que demanda o cuidado ${ }^{1}$. Segundo Boff ${ }^{2}$, o cuidado, historicamente, sempre requisitou do homem a busca pela atenção efetivamente direcionada a si mesmo ou ao outro. A atitude do cuidado significava solicitude, diligência, atenção, bom-trato, preocupação, inquietação e responsabilidade.

O cuidado em saúde pressupóe uma ação integral que náo se restringe apenas às competências e às tarefas técnicas. $\mathrm{O}$ acolhimento, os vínculos de intersubjetividade, a escuta dos sujeitos e o respeito pelo seu sofrimento e história de vida compóem os elementos inerentes à sua constituição, abrindo espaço para a negociação e a inclusão do saber, dos desejos e das necessidades do outro ${ }^{3}$.

O cuidado paliativo é utilizado para designar a forma de assistência interdisciplinar direcionada às pessoas que vivenciam doenças que ameacem a vida. Essa definição criada pela Organização Mundial da Saúde em 1990 e redefinida em 2002 - como sendo uma abordagem multidisciplinar que favorece o aumento da qualidade de vida do paciente e de seus familiares - possibilita compreender que o cuidado é uma dimensão da integralidade em saúde. Nessa perspectiva, o cuidado paliativo preconiza o alívio do sofrimento, com a preservação da autonomia do paciente, especialmente no tratamento da dor e outros sintomas de caráter físico, social, psicológico e espiritual ${ }^{4}$.

O tratamento oncológico pediátrico demanda açóes paliativas intensas e contínuas em razão da necessidade premente de controle da dor e de outros sintomas que acometem crianças e adolescentes com desdobramentos na dinâmica familiar, pois implica uma reorganização da família que necessita conciliar a vida doméstica com as frequentes idas ao hospital'5.

As repetidas internaçóes e os frequentes deslocamentos vão modificando o cotidiano familiar, afastando a criança ou o adolescente das atividades habituais de escola e lazer, além das interferências na situação de trabalho e renda dos seus responsáveis. As mudanças na vida da criança e de sua família, ao se depararem com a doença crônica, não englobam simplesmente alteraçôes orgânicas ou físicas, mas atravessam esse ângulo e promovem alteraçóes emocionais e sociais em toda a família, as quais exigem constantes cuidados e adaptações 5 .

\footnotetext{
${ }^{1}$ Assistente Social Graduada pela Universidade Federal Fluminense (UFF). Niterói (RJ), Brasil. Especializanda da Residência Multiprofissional em Oncologia do Instituto Nacional de Câncer José Alencar Gomes da Silva (INCA)/Ministério da Saúde (MS). Rio de Janeiro (RJ), Brasil. E-mail: gabrielimartins@id.uff.br

${ }^{2}$ Assistente Social do INCA/MS. Doutoranda em Política Social pelo Programa de Pós-Graduação em Serviço Social da Universidade do Estado do Rio de Janeiro (PPGSS/UERJ). Rio de Janeiro (RJ), Brasil. Mestre em Serviço Social e Desenvolvimento Regional pela UFF. Niterói (RJ), Brasil. E-mail: senirsantos@hotmail.com

Endereço para correspondência: Gabrieli Branco Martins. Rua Miguel de Frias, 41- Apartamento 1604 - Bloco 3 - Icaraí. Niterói (RJ), Brasil. CEP: $24220-008$. E-mail: gabrielimartins@id.uff.br
} 
A família, nas suas mais diversas configuraçôes, é construída e reconstruída historicamente por meio das diferentes formas de relaçóes sociais estabelecidas ${ }^{6}$. Nessa concepção, a família é concebida como instituição social composta por pessoas unidas por laços consanguíneos ou não, pois entende-se também por família aquelas "que não têm laços nem de parentesco e nem partilham da mesma unidade de moradia" ${ }^{6}$, mas que são definidas por meio das relaçóes afetivas e pela responsabilidade do cuidado ${ }^{6}$.

A relação entre Estado e Família está presente na história da humanidade como expressão importante da relação privada e a esfera pública da vida social ${ }^{6}$. No atual cenário brasileiro, o Estado vem regredindo a sua participação na provisão de bem-estar dos indivíduos ao transferir a responsabilidade pela proteção social à família ${ }^{7}$. Isto é, o Estado, ao diminuir a sua participação no enfrentamento dos problemas sociais, vem afirmando o papel da família como fonte privilegiada de proteçẫo social ${ }^{7}$.

\section{FAMÍLIA E CUIDADOS PALIATIVOS EM PEDIATRIA: ALGUMAS NOTAS}

Segundo o Global Atlas of Palliative Care at The End of Life $e^{8}$, o cuidado paliativo para crianças e adolescentes possui a mesma essência que o direcionado a adultos. Para ambos, é uma abordagem multidisciplinar visando ao bem-estar físico, psicológico, social e espiritual frente a uma doença que ameace a vida. A especificidade do cuidado paliativo em pediatria é a recomendação de iniciar concomitante ao tratamento curativo (logo após o diagnóstico).

O Oxford Handbook of Palliative Care e também o $A B C$ of Palliative Care $^{10}$ apontam que, no cuidado paliativo pediátrico, o suporte à família deve ser contínuo e intenso, uma vez que a morte de crianças e adolescentes são reconhecidas como tragédias no âmbito familiar em razão da sua precocidade.

O controle da dor e de outros sintomas clínicos já é possível pelo avanço tecnológico, com a disponibilidade de medicamentos potentes e pela eficácia de ações paliativas ${ }^{11}$. Para além dos sintomas físicos, o tratamento oncológico pediátrico deve observar outros determinantes sociais vividos pela criança e sua família, como a situação econômico-financeira, o local onde vive, o acesso aos serviços de saúde, o tipo de trabalho que realiza, a alimentação que dispóe e os diferentes fatores externos e internos que moldam os condicionantes sociais à saúde ${ }^{11}$.

Além disso, cabe ressaltar que a assistência em cuidados paliativos prevê atendimento por meio de equipe especializada, atendimento domiciliar, recursos de medicamentos e insumos, assim como a intersetorialidade com as demais políticas públicas que garantam transporte, hospedagem, alimentação, entre outras ${ }^{12}$.
O tratamento extensivo centraliza o cotidiano da criança/adolescente e de seu grupo familiar em torno do espaço hospitalar e, muitas vezes, implica em rupturas nos projetos de vida de seus diferentes membro 5 . Tomam-se, como exemplo, as famílias monoparentais, chefiadas por mulheres, que exercem a dupla função de prover e cuidar dos seus membros, o que implica no abandono, por parte dessas mulheres, da vida laboral, submetendo-se ao Benefício de Prestação Continuada/LOAS ${ }^{13}$, como único recurso de renda do grupo familiar.

Muitas dessas famílias são de baixa renda, com vínculos precários de trabalho ou em situação de desemprego e subemprego. Famílias com rede pessoal e social restrita, submetidas a uma infraestrutura domiciliar, nem sempre favorável à permanência da criança no local em condiçóes adequadas ao processo de cuidados: casas adaptadas e ambientes acessíveis; abastecimento de água e saneamento básico; fornecimento de energia elétrica; distância entre o domicílio e o centro de tratamento; demandas por hospedagem e transporte; acesso a insumos e medicamentos especiais e excepcionais sem morosidade no processo, entre outras ${ }^{14}$.

No Brasil, a Política Nacional de Atenção Oncológica ${ }^{15}$ introduziu a assistência em cuidados paliativos como um dos elementos dos cuidados ao paciente com câncer. A Portaria $\mathrm{n}^{\circ} 2.339$ de 8 de dezembro de 2005, que instituiu essa política, foi revogada pela Portaria no 874 de 16 de maio de 2013, que estabelece a Política Nacional para a Prevenção e Controle do Câncer na Rede de Atenção à Saúde das Pessoas com Doenças Crônicas no âmbito do Sistema Único de Saúde (SUS) ${ }^{16}$ e mantém o cuidado paliativo como componente da assistência integral ao paciente com câncer. Entretanto, ainda prevalece o modelo hospitalocêntrico e a ausência de políticas públicas destinadas a lidar com o processo de terminalidade ${ }^{17}$.

Nota-se que as políticas sociais não contemplam a realidade vivida pelas famílias em sua totalidade. A inexistência de canais de integração entre as políticas sociais tem gerado uma inoperância em relação às famílias, tendo em vista a garantia de suporte necessário para a efetivação de um atendimento integral de saúde. Não obstante, a família vai assumindo a centralidade da açáo no processo de cuidado, ao mesmo tempo que o modelo hospitalocêntrico predominante vai dificultando a garantia da desospitalização sob a ótica da integralidade e da humanização ${ }^{17}$.

\section{CONCLUSÃO}

O Estatuto da Criança e do Adolescente ${ }^{18}$ define em seu artigo $7^{\circ}$, que são direitos fundamentais das crianças e adolescentes: "a proteção à vida e à saúde, mediante a 
efetivação de políticas sociais que permitam o nascimento e o desenvolvimento sadio e harmonioso, em condiçôes dignas de existência”. Nessa lógica, a garantia do cuidado das crianças e dos adolescentes é dever da família, da sociedade e do Estado.

No cotidiano de trabalho do serviço social em oncologia pediátrica, percebe-se a ausência de açóes paliativas no SUS - principalmente na atenção básica, em que é explícita a carência de oferta desses cuidados por parte da rede pública brasileira de assistência à saúde - quando o lócus é o domicílio, por exemplo.

A pouca oferta de serviços públicos, que forneçam o suporte necessário para a efetivação de um tratamento continuado de crianças e adolescentes, é o principal obstáculo à garantia do cuidado. Nesse sentido, evidencia-se, como desafio, o acesso a insumos, medicaçóes e políticas públicas de assistência, educação, habitação e previdência que estejam de acordo com as necessidades demandadas pelos cuidados paliativos. O dia a dia no serviço de oncologia pediátrica indica que há um distanciamento do que é necessário em termos de suporte social em relação ao que é ofertado.

Observa-se, ainda, uma regressão da participação do Estado na provisão de políticas públicas que garantam às famílias condiçóes objetivas de sobrevivência ${ }^{6}$. Ou seja, no lugar da garantia dos direitos sociais universais, verifica-se a focalização das políticas públicas nos seguimentos mais pauperizados da populaçấo ${ }^{19}$. Nessa reconfiguração, a ausência do protagonismo estatal, no processo de provisáo social, sobrecarrega a família com encargos que superam as suas possibilidades de assumi-los ${ }^{6}$.

Portanto, pode-se pontuar que a assistência em cuidados paliativos pediátricos apresenta muitos desafios relacionados à necessidade de adaptação de ações às diferentes realidades, reconhecimento dos cuidados paliativos como parte integrante e importante da atenção em saúde, reconhecimento do sofrimento vivenciado pelo paciente e familiares e, principalmente, o reconhecimento da morte como parte da vida e náo como fracasso terapêutico ${ }^{20}$.

\section{CONTRIBUIÇÕES}

Ambos os autores contribuíram em todas as etapas do manuscrito.

\section{Declaraçáo de Conflito de Interesses: Nada a Declarar. \\ REFERÊNCIAS}

1. Campos GWS. Consideraçôes sobre a arte e a ciência da mudança: revolução das coisas e reforma das pessoas: o caso da saúde. In: Cecilio LCO, organizadores.
Inventando a mudança na saúde. 2. ed. São Paulo: Hucitec; 1997.

2. Boff L. Saber cuidar: ética do humano: compaixão pela terra. 9. ed. Petrópolis: Vozes; 2003.

3. Pinheiro R, Mattos RA. Cuidado: as fronteiras da integralidade. 3. ed. Rio de Janeiro: Hucitec; 2005.

4. World Health Organization. National cancer control programmes: policies and managerial guidelines. 2. ed. Geneva: WHO; 2002.

5. Silva MAS, Collet N, Silvia KL, Moura, FM. Cotidiano da família no enfrentamento da condição crônica na infância. Acta Paul Enfermagem. 2010; 23(3):359-65.

6. Teixeira SM. Política Social contemporânea: a família como referência para as políticas sociais e para o trabalho social. In: Mioto RCT, Campos MS, Carloto $\mathrm{CM}$, organizadores. Familismo, direito e cidadania: contradiçôes da política social. São Paulo: Cortez; 2015. p. 211-39.

7. Mioto RC. Estudos socioeconômicos. In: Conselho Federal de Serviço Social; Associação Brasileira de Ensino e Pesquisa em Serviço Social. Serviço Social: Direitos Sociais e competências profissionais. Brasília, DF: CFESS; 2009. p. 481-496.

8. World Health Organization. Global Atlas on Palliative Care at the End of Life. Geneva: WHO; 2014.

9. Sibson K, Craig F, Goldman A. Palliative care for children. In: Faull C, Carter Y, Daniels L, editors. Handbook of palliative care. 2nd ed. Malden: Blackwell Publishing; 2005. p. 295-16.

10. Goldman A. Palliative Care for Children. In: Fallon M, Hanks G. ABC of Palliative Care. 2nd ed. Malden: Blackwell Publishing; 2006. p. 48-51.

11. Brito MA, Soares EO, Rocha SS, Figueiredo, MLF. Cuidados Paliativos em pediatria: um estudo reflexivo. Rev Enferm UFPE online. 2015, 9(3):7155-60.

12. Silva RCF. Cuidados paliativos oncológicos: reflexóes sobre uma proposta inovadora na atenção à saúde [dissertação]. Rio de Janeiro: Fundação Oswaldo Cruz; 2004.

13. Brasil. Lei no 8.742, de 7 de dezembro de 1993. Diário Oficial da União, Brasília, DF, 8 dez. 1993. Seção 1, p. 18769.

14. Grabois MF. $\mathrm{O}$ acesso a assistência oncológica infantil no Brasil [tese]. Rio de Janeiro: Fundação Oswaldo Cruz; 2011.

15. Brasil. Ministério da Saúde. Portaria GM no 2439 de 8 de dezembro de 2005. Diário Oficial da União, Brasília, DF, 9 dez. 2005. Seção 1, p. 80.

16. Brasil. Portaria GM no 847 de 16 de maio de 2013. Diário Oficial da União, Brasília, DF, 17 maio 2013. Seção 1, p. 188.

17. Rabello CAFG, Rodrigues PHA. Saúde da família e cuidados paliativos infantis: ouvindo os familiares de 
crianças dependentes de tecnologia. Cien Saúde Coletiva. 2015, 15(2):379-88.

18. Brasil. Lei no 8069 de 13 de julho de 1990. Diário Oficial da União, Brasília, DF, 16 jul. 1990. Seção 1, p. 13563.
19. Behring ER, BoschettI I. Política social: fundamentos e história. 4. ed. São Paulo: Cortez; 2008.

20. Silva RCF, Hortale VA. Cuidados Paliativos oncológicos: elementos para o debate de diretrizes nesta área. Cad Saúde Pública. 2006; 22(10):2055-66. 